www.jmscr.igmpublication.org

Impact Factor 5.244

Index Copernicus Value: 83.27

ISSN (e)-2347-176x ISSN (p) 2455-0450

crossref DOI: _https://dx.doi.org/10.18535/jmscr/v4i10.77

Journal Of Medical Science And Clinical Research

\title{
Enhancing Parental Self-management of Child's Seizure Disorder by a Structured Educational Intervention: a Randomized Controlled Trial
}

\author{
Authors \\ Ms Merin Sara Mathew ${ }^{1}$, Ms Milu Elsa Paul ${ }^{2}$, Dr Anna Mathew ${ }^{3}$, Dr M C Mathew ${ }^{4}$, \\ Mrs. Susan Sosa Jacob $^{5}$, Mr Saravana Kumar Velusamy ${ }^{6}$ \\ ${ }_{1,2} 3^{\text {rd }}$ year medical student, MOSC Medical College, Kolenchery, Kochi, Kerala, India \\ ${ }^{3}$ Professor, Department of Pharmacology, MOSC Medical College, Kolenchery, Kochi, Kerala, India \\ ${ }^{4}$ Professor, Department of Developmental Paediatrics and Child Neurology, MOSC Medical College \\ Kolenchery, Kochi. Kerala. 682311 India \\ ${ }^{5}$ Developmental Psychologist, Department of Developmental Paediatrics and Child Neurology, MOSC \\ Medical College, Kolenchery, Kochi. Kerala 682311 India \\ ${ }^{6}$ Biostatistician, Dept of Biostatistics, Christian Medical College, Vellore. Tamil Nadu. 632 002. India \\ Corresponding Author \\ Dr Anna Mathew \\ Professor, Department of Pharmacology, MOSC Medical College, Kolenchery, Kochi, Kerala, India
}

Email: 350south@gmail.com,Tel: +919442221950

\begin{abstract}
Seizure disorder is a chronic paediatric condition which requires parental commitment to self-management to ensure quality of life for the child and the family. Hence this prospective, parallel group, randomized controlled clinical trial was planned to study whether structured education enhances parental self-management of their child's seizure disorder.

Sixty four parents of children, below 18 years of age, attending the Developmental Paediatrics and Child Neurology outpatient department, in a tertiary care centre in South India, who gave written informed consent were recruited into the study after institutional ethical committee approval was received. The department is located in a rural area and serves children with special needs who come from various parts of this state and the neighbouring states. The instrument used to assess efficacy of self-management was the Paediatric Epilepsy Self- Management Questionnaire (PEMSQ) (in the local language) after permission was obtained from the author.

The first contact PEMSQ was administered on recruitment to the study by an independent assessor. The participants were randomized by permuted block randomization into two groups, the intervention group and the comparator group. Allocation was concealed from the assessor. After 72 hours the follow up PEMSQ was administered by the blinded assessor. The improvement in the follow up score compared to the first contact score was recorded and compared to find if there was a significant difference between the two groups. The nonparametric Wilcoxon Mann Whitney U test was used to compare the scores statistically using SPSS version 16.

Our study showed significant improvement in the parental scores for self-management using the PEMSQ. There was also improvement in all the four PEMSQ sub-scalesi. Knowledge of seizure disorder, ii. commitment to adherence to treatment, iii. beliefs about efficacy of drugs, and iv. barriers to treatment

Thus we conclude that there is a significant enhancement of parental self-management following the structured education given to the intervention group compared to the comparator group.
\end{abstract}




\section{Introduction}

Seizures constitute the commonest neurological problem in children. Appropriate management of childhood epilepsy is essential to improve the quality of life of these children. ${ }^{1}$ Children with uncontrolled seizures also experience significant morbidity and face social stigma and discrimination diminishing their quality of life. ${ }^{2}$ About $65 \%$ of children with newly diagnosed epilepsy achieve sustained freedom from seizures with the initially prescribed antiepileptic drug (AED). An additionnal $15-20 \%$ becomes seizure free with subsequently prescribed AEDs, while the remainder cannot achieve seizure control with available medications. ${ }^{3}$ The goal of epilepsy drug treatment is to optimize seizure control and quality of life while minimizing treatment toxicity ${ }^{4}$. It is also known that antiepileptic drug non-adherence predicts paediatric epilepsy seizure outcomes. ${ }^{5}$

When a child has a chronic illness like seizure disorder, the care-givers, which are usually the parents have to play a major role in the treatment of the child under the supervision of the medical team. If they are enabled in this process of "selfmanagement" they will be able to assume control of the illness and its symptoms and minimize its effects on health and quality of life. Studies show that self-management of chronic pediatric conditions is a great challenge with a high prevalence of poor self-management and nonadherence. ${ }^{6}$ The concept of self-management is important because epilepsy management primarily occurs in the home environment and not in clinic settings. The parents/caregivers are entirely responsible for adhering to the doctor's treatment advice and so it is important that parents/ caregivers understand that continuation of the seizure medication without interruption is essential to the child being seizure free. The reason why parents do not adhere to the prescribed therapy is known to be poor self-management skills and lack of knowledge of the basic facts about the treatment of seizure disorder. ${ }^{6}$

Non-adherence in children with seizures presents a potential ongoing challenge for achieving seizure control. The rates for non-adherence to anti-seizure medicines have been reported to be between $12 \%$ to $35 \%$ and $58 \%$ of children with newly diagnosed epilepsy demonstrated persistentnon-adherence during the first six months of therapy. ${ }^{7}$ In a systematic review of epilepsy selfmanagement interventions Lewis et al state that parents and children knowingly or unknowingly take risks with their epilepsy and there is a need for innovative individually tailored interventions to address these challenges ${ }^{8}$. Studies have examined two main types of interventions to help patients with adherence to antiepileptic medicateons - educational and behavioural modification. ${ }^{9}$

Self-management of seizure disorder refers to the activities required to control seizures and reduce side effects, including taking antiepileptic drugs, engaging in healthy lifestyle behaviours (e.g., good sleep hygiene), active participation in decision making with the health care team, and managing stress. We used the Paediatric Epilepsy Self- Management Questionnaire (PEMSQ) by Modi et al (with permission from the author) to assess how effectively the parent carries out the seizure medication plan of the child. The PEMSQ is a standardized tool with 27 items validated for caregivers of children with epilepsy ${ }^{10}$.The items are classified into four scales to assess four domains of adherence. They are i. knowledge of seizure disorder and the treatment, ii. commitment to adhere to the treatment plan, iii. Beliefs about efficacy of drugs, and iv. barriers to treatment.

The PEMSQ is a standardized tool which has strong psychometric properties, including good internal consistency among scales and construct validity with objective and subjective measures of adherence. Thus, the PEMSQ is likely to have both clinical and research utility in neurology practices. $^{5}$

Parents of children on treatment with seizure medication, attending the out-patient service of the Developmental Paediatrics and Child Neurology Department were recruited to this randomized controlled trial with two arms, the intervention group, which provides planned structured education to parents and the nonintervention group. Parental scores using the 
Paediatric Epilepsy Self- Management Question naire (PEMSQ) before and after receiving the intervention were used to compare the two groups. To comply with ethical practices, the participants from the group that did not receive the intervention received the hand-out on the importance of adherence to seizure medication plan and the medication diary on completion of the follow-up questionnaire. Thus all participants will benefit from the study.

\section{Objectives}

1. To assess parental self-management of their child's seizure disorder using the Paediatric Epilepsy Self- Management Questionnaire (PEMSQ).

2. To determine whether Structured Educational Intervention and teaching about keeping a medication diary enhances parental adherence to the Child's Seizure Medication Planusing the PEMSQ.

\section{Materials \& Methods}

This study was conducted as a prospective, parallel group, single blinded randomized controlled trial. The study was approved by the institutional review board of this medical college and received institutional ethical committee approval. It has been approved by the Indian Council of Medical Research in the Short term studentship 2014 programme (ICMR ID: 201401749). This clinical trial has also been registered with the Clinical Trials Registry of India (CTRI /2014/06/004656 dated 05.06.2014).

All parents of children below the age of 18 years, taking anti-seizure medication, more who gave written informed consent were eligible to be recruited into the study. Parents who were qualified health professionals themselves were excluded from the study. Participants were recruited from the outpatient service of the Developmental Pediatrics and Child Neurology department of this tertiary care centre, in a rural area in South India from July to August 2014.
The sample size calculated by nMaster Sample size Calculation Software version $2.0^{10}$ for the Non Parametric Two Group Wilcoxon Mann Whitney U-Test was found to be 32 in each arm of the study. The study will have a power of $80 \%$ and an alpha error of $5 \%$.

All participants were interviewed after their consultation and regular counselling regarding seizure medication from the treating doctors and therapists. The demographic data, details of seizure disorder, medication history and other details were recorded The first contact PEMSQ was administered to all participants by the assessor.

The participants were randomly allocated to one of the two arms of the study by permuted block randomization. The allocation sequence was concealed from the assessor.

Group A. This was the intervention group where participants received structured education in addition to the regular input from the treating medical team

Group B. This was the comparator group which received only the regular input from the medical team

The participants allocated to the intervention group received the structured education by the investigator using good counselling techniques. The structured education included a prepared talk on anti-seizure medication and self-management, a session on how to keep a medication diary. Participants also received a printed hand-out on the importance of adhering to seizure-medication and a seizure medication diary.

All participants were administered the follow-up questionnaire after 72 hours by a blinded assessor following which the participants in the comparator group were also given the hand-out and the seizure medication diary. 
All parents of children who receive anti-seizure medication and attending the Developmental Pediatrics out-patient unit

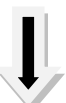

Parents were welcomed and informed consent was received. Parents who fulfill the selection criteria were randomized into two groups $A$ and $B(n=64)$

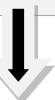

The PEMSQ questionnaire was filled by a blinded assessor.

The parents were then randomized into two groups by permuted block randomization

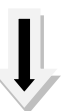

\section{Group A}

32 participants received

- Structured education

- Seizure medication handout and

- Teaching on maintaining a medication log book

\section{Group B}

32 participants received only standard care

The PEMSQ questionnaire was filled again by a blinded assessor after 72 hours.

$$
(n=64)
$$

The PEMSQ questionnaires were scored and the means obtained for the four sub-scales. The Data was entered into an Excel spread sheet for statistical analysis.

The PEMSQ is a valid and reliable tool to assess Pediatric Epilepsy Medication Self-Management. It has a total of 27 items which measures four domains of parental awareness with the help of a Likert scale.
$>$ Scale 1. Disease and Treatment Knowledge and Expectations (8 items)

$>$ Scale 2. Adherence to Medications \& Clinical Appointments, (8 items)

$>$ Scale 3. Beliefs about Medication Efficacy (8 items) 
Scale 4. Barriers to Treatment (3 items)

a) Talk on Adherence to Seizure Plan: The investigator engaged each family in a 10 minute session on the Topic "Adherence to the Seizure Medication Plan." The talk has been given in the local language and included the four aspects of the PEMSQ.

b) Seizure Medication Diary: The investigator introduced the parents to the seizure medication diary and encouraged them to make an entry at the end of each week regarding the medication given to the child that week, paying attention to when doses were missed and other changes made in the plan.

c) Seizure Medication Hand-out: The investigator also gave the family a handout prepared by the investigator on "Selfmanagement of Seizure Disorder" with additional information about seizure $\mathrm{m}$ pecially concerning adverse effects and their early recognition.

\section{Statistical Analysis}

All demographic data was found to be balanced in the two groups. Normal distribution assumption over intervention arm was tested using box plots and normality test. The scores of the two groups were compared using the Non Parametric Two Group Wilcoxon Mann Whitney U-Test to see if there is a significant difference between the group that received the education and the group that did not.

\section{Observations \& Results}

Descriptive statistics were used to characterize demographic variables in both the groups. Table1 and figures1, 2, 3 and 4 give the demographic details while tables 2 and table 3 give the outcome details.

Table 1. Baseline Demographic Characteristics of Study Participants.

\begin{tabular}{|c|c|c|c|}
\hline Variables & Group A & Group B & Total \\
\hline $\begin{array}{l}\text { c } \\
\text { Age }[\text { Mean } \pm \text { SD] }\end{array}$ & $6.97 \pm 3.50$ & $6.28 \pm 3.26$ & $6.62 \pm 3.37$ \\
\hline $\begin{array}{l}\text { Sex }[\text { Number }(\%)] \\
\text { Male } \\
\text { Female }\end{array}$ & $\begin{array}{l}21(65.6 \%) \\
11(34.4 \%) \\
\end{array}$ & $\begin{array}{c}23(71.9 \%) \\
9(28.1 \%)\end{array}$ & $\begin{array}{l}44(68.8 \%) \\
20(31.2 \%) \\
\end{array}$ \\
\hline $\begin{array}{l}\text { Socio-economic status [Number }(\%)] \\
\text { Eow } \\
\text { Middle } \\
\text { High }\end{array}$ & $\begin{array}{l}8(25 \%) \\
16(50 \%) \\
8(25 \%) \\
\end{array}$ & $\begin{array}{c}8(25 \%) \\
19(59.4 \%) \\
5(15.6 \%) \\
\end{array}$ & $\begin{array}{l}16(25 \%) \\
35(54.7 \%) \\
13(20.3 \%) \\
\end{array}$ \\
\hline $\begin{array}{l}\text { Educational Status [Number }(\%)] \\
\text { Father } \\
\text { Undergraduate } \\
\text { Graduate } \\
\text { Mother } \\
\text { Undergraduate } \\
\text { Graduate }\end{array}$ & $\begin{array}{l}10(31.25 \%) \\
22(68.75 \%) \\
17(53.1 \%) \\
15(46.9 \%)\end{array}$ & $\begin{array}{l}13(40.8 \%) \\
19(59.4 \%) \\
14(43.7 \%) \\
18(56.3 \%)\end{array}$ & $\begin{array}{l}23(35.9 \%) \\
41(64 \%) \\
31(48.4 \%) \\
33(51.5 \%)\end{array}$ \\
\hline $\begin{array}{l}\text { Primary Care Giver [Number (\%)] } \\
\text { Father } \\
\text { Mother }\end{array}$ & $\begin{array}{l}10(31.2 \%) \\
22(68.8 \%)\end{array}$ & $\begin{array}{c}8(25 \%) \\
24(75 \%)\end{array}$ & $\begin{array}{l}18(28.1 \%) \\
46(71.9 \%)\end{array}$ \\
\hline $\begin{array}{l}\text { Duration of Anti-seizure Medication [Number }(\%)] \\
<6 \text { months } \\
6 \text { months }-1 \text { year } \\
1-2 \text { years } \\
>2 \text { years }\end{array}$ & $\begin{array}{l}11(34.4 \%) \\
7(21.9 \%) \\
6(18.8 \%) \\
8(25 \%)\end{array}$ & $\begin{array}{ll}6 & (18.8 \%) \\
10 & (31.2 \%) \\
7 & (21.9 \%) \\
9 & (28.1 \%)\end{array}$ & $\begin{array}{l}17(26.6 \%) \\
17(26.6 \%) \\
13(20.3 \%) \\
17(26.6 \%)\end{array}$ \\
\hline $\begin{array}{l}\text { Type of Therapy [Number }(\%)] \\
\text { Monotherapy } \\
\text { Polytherapy }\end{array}$ & $\begin{array}{c}26(81.2 \%) \\
6(18.8 \%)\end{array}$ & $\begin{array}{l}18(56.2 \%) \\
14(43.8 \%)\end{array}$ & $\begin{array}{l}44(68.8 \%) \\
20(31.2 \%)\end{array}$ \\
\hline $\begin{array}{l}\text { Maintaining Seizure Med. Log [Number (\%)] } \\
\text { Yes } \\
\text { No }\end{array}$ & $\begin{array}{c}9(28.1 \%) \\
23(71.9 \%)\end{array}$ & $\begin{array}{c}9(28.1 \%) \\
23(71.9 \%)\end{array}$ & $\begin{array}{l}18(28.1 \%) \\
46(71.9 \%)\end{array}$ \\
\hline
\end{tabular}


Baseline demographic data did not need any adjustments as the first contact outcome measures in the PEMSQ scores were well balanced.

Out of the total of 64 children $68.8 \%$ were males and $32.2 \%$ were female however the Male Female ratio of 2:1 was almost similar in both Group A and group B.

Of the 64 children nearly $70 \%$ were on treatment with one drug (mono-therapy) while the remaining were on more than one drug (poly-therapy) with anti-epileptic drugs. Regarding duration of treatment, 53\% were receiving anti-seizure medication for a year or less, while $57 \%$ were taking medication for more than a year.

Figure 2. Age Distribution of Participants

\section{AGE DISTRIBUTION}

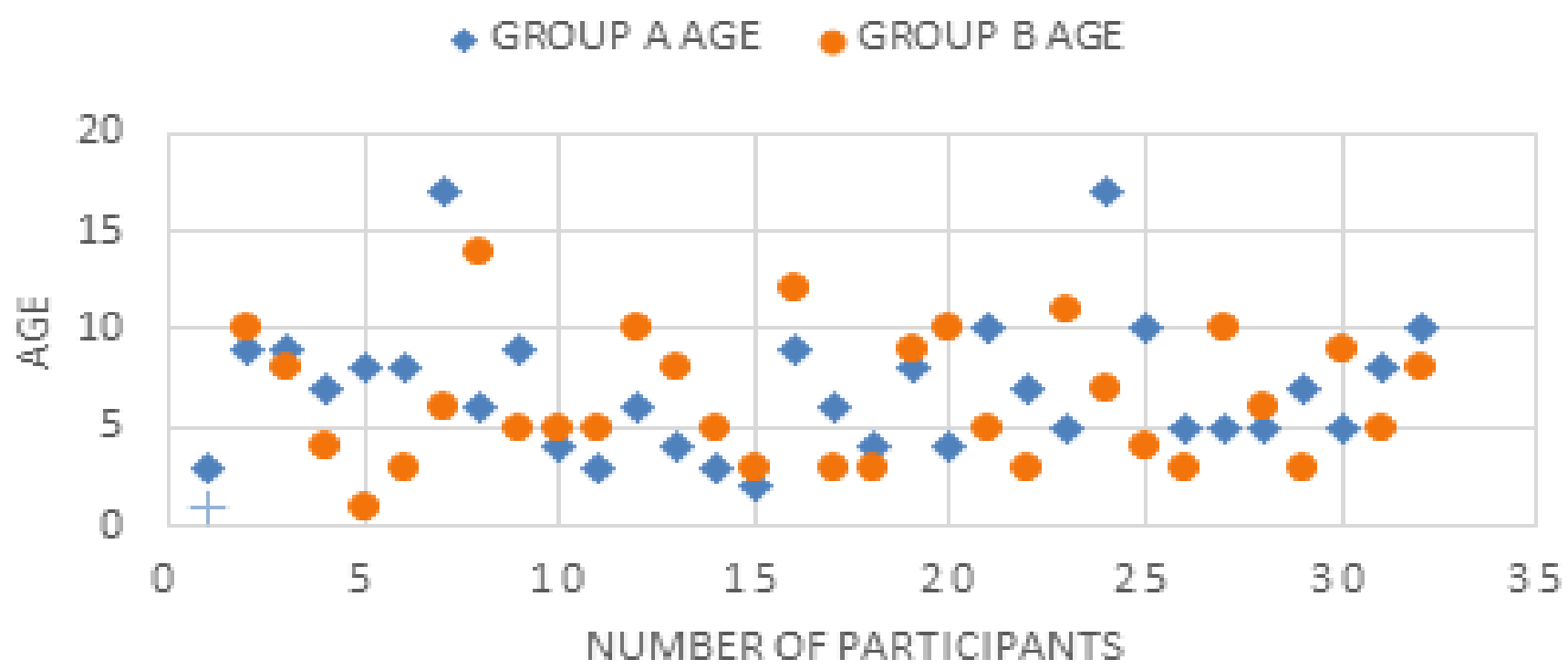

The age distribution of participants was normal in both Group A and Group B and the mean age was found to be $6.97 \pm 3.50$ in Group A and $6.28 \pm 3.26$ in Group B. to be $6.97 \pm 3.50$ in Group A and $6.28 \pm 3.26$ in Group B.

The scores in the PEMSQ were added together to make up the total score for a particular scale. Items on the Barriers to Medication Adherence scale were scored in reverse for consistency. The total score included the sum of all 27 questions.

Total scores. There wasa significant improvement $(\mathrm{p}=.005)$ in the total PEMSQ self-management scores following structured education.

Subscale scores. There were eight questions in the disease and treatment knowledge and expectations subscale, beliefs about medication efficacy sub-scale and in the barriers to treatment subscale and was significant improvement in the scores for the eight questions $(\mathrm{p}=.008),(\mathrm{p}=.004))$ and $(\mathrm{p}=.005)$ also showed significant improvement in scores with education. However the improvement in scores in the sub-scale on adherence to medications \&clinical appointments $(\mathrm{p}=.503)$ was not statistically significant.

The subscales for disease and treatment knowledge and expectations ( $\mathrm{p}=.008)$, beliefs about medication efficacy $(\mathrm{p}=.004))$ and barriers to treatment $(\mathrm{p}=.005)$ also showed significant improvement in scores following the structured education. However the improvement seen in the scores in the sub-scale on adherence to medications \&clinical appointments $(\mathrm{p}=.503)$ was not statistically significant 
Table 3. Mean Scores of PEMSQ - Total Score and 4 Scales

\begin{tabular}{|c|c|c|c|c|c|}
\hline \multirow[b]{2}{*}{ PEMSQ Domains } & \multirow[b]{2}{*}{$\begin{array}{l}\text { Study } \\
\text { Group }\end{array}$} & $\begin{array}{l}\text { First contact } \\
\text { PEMSQ }\end{array}$ & Follow-up PEMSQ & \multirow{2}{*}{\begin{tabular}{|} 
Improvement \\
in Mean \\
Scores in \\
Follow-up \\
PEMSQ
\end{tabular}} & Test Statistics \\
\hline & & Mean \& SD & Mean & & $\begin{array}{c}\text { Wilcoxon Mann } \\
\text { Whitney U test 'p' } \\
\text { value }\end{array}$ \\
\hline \multirow{2}{*}{$\begin{array}{c}\text { Scale 1 } \\
\text { Disease and Treatment } \\
\text { Knowledge and Expectations }\end{array}$} & A & & $35.41 \pm 3.46$ & 5.19 & \multirow[t]{2}{*}{.008} \\
\hline & B & $31.41 \pm 5.05$ & $32.44 \pm 4.42$ & 1.03 & \\
\hline \multirow{2}{*}{$\begin{array}{c}\text { Scale 2 } \\
\text { Adherence to Medications \& } \\
\text { Clinical Appointments }\end{array}$} & A & $32.38 \pm 4.70$ & $35.63 \pm 3.50$ & 3.25 & \multirow[b]{2}{*}{.503} \\
\hline & B & $34.28 \pm 5.16$ & $34.53 \pm 4.96$ & 0.25 & \\
\hline \multirow{2}{*}{$\begin{array}{c}\text { Scale } 3 \\
\text { Beliefs about Medication } \\
\text { Efficacy } \\
\end{array}$} & A & $12.38 \pm 1.81$ & $13.63 \pm 1.76$ & 1.25 & \multirow[b]{2}{*}{.004} \\
\hline & B & $12.62 \pm 2.20$ & $12.84 \pm 2.07$ & 0.22 & \\
\hline \multirow{2}{*}{$\begin{array}{c}\text { Scale } 4 \\
\text { Barriers to Treatment }\end{array}$} & A & $31.09 \pm 5.42$ & $35.00 \pm 4.20$ & 3.91 & \multirow{2}{*}{.005} \\
\hline & B & $30.53 \pm 6.50$ & $31.16 \pm 6.06$ & 0.63 & \\
\hline \multirow[b]{2}{*}{ TOTAL SCORE } & $\mathbf{A}$ & $106.09 \pm 15.79$ & $119.91 \pm 10.85$ & 13.82 & \multirow[b]{2}{*}{.005} \\
\hline & B & $108.53 \pm 13.40$ & \pm 12.51 & 2.44 & \\
\hline
\end{tabular}

Total PEMSQ Score showed a significant improvement following structured education.

Scale 1 (Items 1-8 on the PEMSQ) showed a significant increase in the mean score in Group A (0.008)

Scale 2. (Items 9-16 on the PEMSQ) showed improvement in scores in Group A over group B, however the improvement was not statistically significant (0.503)

Scale 3. (Items 17-19 on the PEMSQ) showed a significant improvement in the mean score in Group A (0.004)

Scale 4. (Items 20 -27) on the PEMSQ also showed significant improvement in scores.

\section{Discussion}

In our study there were no significant differences in the demographic details between the intervention and the comparator groups, such as age, gender, socio-economic status, educational status of parents. We found a greater number of boys in the study compared to girls (2:1). This reflects the pattern in the developmental paediatrics and child neurology department of this institution where the ratio of male children to female children in the year 2013-2014 was 2.1:1. Of the 64 parents who participated only $28 \%$ had kept a record of the child's medication. Hence we hope our effort in providing teaching about the medication diary will enable the remaining $72 \%$ to become aware of the need to maintain a seizure- medication log. Of the 64 children nearly $70 \%$ were on treatment with one drug while the remaining were on poly-therapy with antiepileptic rugs. Though there was a difference between the children receiving mono therapy in the two groups (81\% in Group A and $56 \%$ in Group B) adjustment was not considered necessary as the first contact PEMSQ scores were well balanced.

\section{PEMSQ Scores}

There was a significant improvement in total PEMSQ scores $(\mathrm{p}=.005)$ in the intervention group (13.82) compared to the comparator group (2.44). This is a clear indication of the effectiveness of the structured education given. 
The improvement in the scores in Sub-scales were Scale 1 - Group A 5.19, Group B $1.03(\mathrm{p}=.008)$; Scale 2 - Group A 3.25, Group B $0.25(\mathrm{p}=.503)$; Scale 3 - Group A 1.25, Group B $0.22(\mathrm{p}=.004)$; Scale 4 - Group A 3.91, Group B 0.63 ( $\mathrm{p}=.005)$. In a study by Modi et al with 124 children ranging from 2 to 12 years the mean age was found to be 7.2 years while our study shows a mean score of 6.62 years. This may be because the parents were recruited from a specialty out-patient service rather than a general pediatric out-patient department. This study also showed that family socio-economic status was a significant predictor of adherence to treatment and that the primary care giver was the mother in $85 \%$ of the families. In our study $75 \%$ of families came from the middle and high income group and in $72 \%$ of them the mothers were the primary care-giver. ${ }^{6}$

Our study showed that regular planned structured education during the hospital visit can improve parental self-management of their child's epilepsy treatment.

It is a good practice for all parents of children with seizure disorder on anti-epileptic drugs to maintain a seizure medication diary where details of the drugs administered to the child can be recorded. This practice is now being implemented in our institution in the developmental paediatrics and child neurology department.

\section{Conclusions}

From this study we were able to assess parental self-management of their child's seizure disorder in the four domains of disease, treatment knowledge and expectations, adherence to medications and clinical appointments, beliefs about medication efficacy and barriers to treatment.

Comparison of the first contact and follow-up of the PEMSQ scores showed there was significant improvement of total parental scores following the structured education in the intervention group compared to the comparator group. Parental scores were higher in all the four domains in the educated group compared to the group that did not receive the structured education.
This implies the importance of structured education to communicate aspects of selfmanagement to the parents. The importance of documentation is illustrated to the parents using the medication diary. The printed hand-out is an additional educational tool to help the parents to adhere to the anti-epileptic drug therapy of their child.

\section{Acknowledgements}

This work was accepted for the Indian Council of Medical Research (ICMR) - Short term Studentship award 2014 (ICMR - STS 2014 ID: 2014 - 01749) and the report has already been submitted to the ICMR.

We would like to acknowledge our gratitude to the principal, medical superintendent and management of the MOSC Medical College, the research department and the developmental paediatrics and child neurology department for support and encouragement given to conduct this study.

The authors acknowledge the help and support given by Mr. Thomas Jeo Joseph, $3^{\text {rd }}$ year medical student, MOSC Medical College, Kolenchery.

\section{References}

1. Naik N, Expert Committee on Pediatric Epilepsy, Indian Academy of Pediatrics. Guidelines for Feb 4;291(5):615-20.

2. Morita DA, Glauser TA, Modi AC. Development and validation of the Pediatric Epilepsy Side Effects Questionnaire. Neurology. 2012 Sep 18;79(12):1252-8.

3. Modi AC, Pai AL, Hommel KA, Hood KK, Cortina S, Hilliard ME, Guilfoyle SM, Gray WN, Drotar D. Pediatric selfmanagement: a framework for research, practice, and policy. Pediatrics. 2012 Feb;129(2):e473-85.

4. Modi A C, Wu YP, Rausch JR, Peugh JL, Glauser TA. Antiepileptic Drug Nonadherence predicts Pediatric Epilepsy Seizure Outcomes. Neurology. 2014 Oct 29. Pii: 10.1212/WNL.0000000000001023.[Epub ahead of print] 
5. Modi A C, Monahan S, Daniels D, Tracy A, Glauser TA. Development and Validation of the Pediatric Epilepsy Medication Self-Management Questionnaire. Epilepsy Behav. 2010 May ; 18(1-2): 94-99.

6. Aneja S1, Sharma S. Newer anti-epileptic drugs. Indian Pediatr. 2013 Nov 8;50(11):1033-40.

7. Modi AC, Rausch JR, Glauser TA. Patterns of Non-adherence to Antiepileptic Drug Therapy in Children With Newly Diagnosed Epilepsy .. JAMA 2011 April 27; 305(16): 1669-1676.

8. Schilling LS, Grey M, Knafl KA. The concept of self-management of type 1 diabetes in children and adolescnets: An evolutionary concept analysis. Journal of Advanced Nursing. 2002; 37(1):87- 99.

9. Al-Aqueel S, Al-Sabhan J. Strategies for improving adherence to antiepileptic drug treatment in patients with epilepsy. Cochrane Database Syst Rev. 2011 Jan $19 ;(1)$.

10. Sample size calculated by nMaster software,version 2.0 produced by the Department of Biostatistics, Christian Medical College, Vellore 632 002,TN.

11. Efird J. Blocked Randomization with Randomly Selected Block Sizes. Intl J Environ Res Public Health 2011;8(1): 1520.

12. Glauser T, Ben-Menachem E, Bourgeois B,et al, Treatment Guidelines:Evidence based analysis of antiepileptic drug efficacy and effectiveness as initial monotherapy for epileptic seizures and syndromes; Epilepsia 2006; Vol-47,1094-1120.

13. Carpay HA, Arts WF, Geerts AT, Stroink $\mathrm{H}$, Brouwer OF, Boudewyn Peters AC, van Donselaar CA. Epilepsy in childhood: an audit of clinical practice. Arch Neurol. 1998 May;55(5):668-73. 